\title{
Influence of ethnic origin on respiratory distress syndrome in very premature infants
}

\author{
Valia Kavvadia, Anne Greenough, Gabriel Dimitriou, Richard Hooper
}

\begin{abstract}
Aim-To determine whether the incidence of respiratory distress syndrome (RDS) is related to ethnic origin in very premature infants ( $\leqslant 32$ weeks of gestational age and birthweight $\leqslant 2.0 \mathrm{~kg}$ ).

Method-A retrospective cohort study was performed to determine the incidence of respiratory disorders in African, Caribbean, and caucasian infants. An African infant was matched with two infants (one of Caribbean and one of caucasian descent) for gestational age and birth order and, if several eligible matching infants were found, for gender and approximate birth date. Fifty African infants (median gestational age 28 weeks, range 23-32) were matched with an infant of Caribbean and one of caucasian descent.

Results-Compared with the incidence of RDS in African infants (40\%), that in caucasian infants $(75 \%)$ was significantly higher $(p<0.05)$, while the incidence in the Caribbean infants (54\%) did not differ significantly. Regression analysis showed that ethnic origin was related to the occurrence of RDS independent of gestational age, size for dates, antenatal steroids, hypertension during pregnancy, premature rupture of membranes, maternal smoking, mode of delivery and infant gender.
\end{abstract}

Conclusion-The enhanced lung maturation found in certain ethnic groups, even when born prematurely, has implications for clinical management.

(Arch Dis Child Fetal Neonatal Ed 1998;78:F25-F28)

Keywords: respiratory distress syndrome; ethnic origin, prematurity

Black infants have a lower incidence of respiratory distress syndrome(RDS) than white infants. $^{12}$ This seems to be due to enhanced lung maturation. ${ }^{3}$ That effect, however, may be restricted to relatively mature infants. ${ }^{4}$ Logistic regression analysis of 298 infants born between 24 to 35 weeks of gestation failed to demonstrate a lower incidence of RDS in white rather than black babies. ${ }^{4}$ A further study ${ }^{5}$ showed accelerated lung maturation only in infants beyond 32 weeks of gestation. The situation may also be complicated by the exact ethnic origin of the infant. Lung maturation occurred more rapidly in Ethiopians, but more slowly in South African blacks, than in white or black infants from the United States. ${ }^{6}$ The aim of this study was, therefore, to assess if ethnic origin did affect the rate of lung maturation, as evidenced by the occurrence of RDS, in very prematurely born infants of African, caucasian, or Caribbean descent.

\section{Methods}

Infants who had been admitted to the neonatal intensive care unit, and of less than 33 weeks of gestational age were retrospectively identified between 1991 and 1995. In 60 infants both parents were of African descent. Matching for gestational age and birth order was then attempted for each subject with an infant whose parents were both of caucasian descent and a second infant whose parents were both of Caribbean descent. If several infants matched a subject, a same sex infant and then the one closest in birth date was chosen. Matching proved impossible for 10 African infantsthree sets of twins and four infants all of 31 weeks of gestational age. The latter problem was due to the limited number of Caribbean infants in that age group.

Maternal and newborn inpatient hospital records served as the information source for our study. Data obtained from the mothers' hospital records included parental ethnicity, antenatal steroids (a standard regimen was used throughout the study period), hypertension during pregnancy, prolonged rupture of membranes ( $>24$ hours) (PROM), antepartum haemorrhage, smoking habit, birth order, mode of delivery and gestational age of the infant calculated from the date of the mother's last menstrual period to that of birth.

The infant's hospital records provided information on birthweight, gender, occurrence and diagnosis of respiratory failure, requirement for ventilation and supplementary oxygen and discharge status (alive or deceased). Infants were described as small for gestational age (SGA) if their weight was less than the third percentile on the Gairdner-Pearson growth curves. The diagnosis of the infant's respiratory failure had been made by the clinician in charge using standard criteria, in particular the appearance of the infant's chest radiograph taken within four hours of birth. The chest radiograph appearance was independently reported by one paediatric radiologist. Respiratory distress syndrome (RDS) was diagnosed if the infant developed respiratory problems within four hours of birth, which persisted for longer than 24 hours; or if the infant's chest radiograph appearances showed symmetrical granular opacities in both lung fields with a superimposed air bronchogram, ${ }^{7}$ and the infant had received at least one dose of surfactant replacement therapy. Transient tachypnoea of the newborn (TTN) was diagnosed if the infant was tachypnoeic and 
Table 1 Demographics according to ethnic origin (data expressed as median (range) or $n$ (\%))

\begin{tabular}{lccc}
\hline & African $n=50$ & Caucasian $n=50$ & Carribbean $n=50$ \\
\hline Gestational age (weeks) & $28(23-32)$ & $28(23-32)$ & $28(23-32)$ \\
Birthweight (kg) & $1.03(0.57-2.0)$ & $1.0(0.50-1.99)$ & $0.973(0.47-1.76)$ \\
Small for gestational age & $5(10)$ & $9(18)$ & $9(18)$ \\
Males & $20(40)$ & $21(42)$ & $24(48)$ \\
Vaginal delivery & $33(66)$ & $28(56)$ & $28(56)$ \\
Maternal hypertension & $7(14)$ & $10(20)$ & $12(24)$ \\
PROM & $13(26)$ & $7(14)$ & $8(16)$ \\
Maternal smoking & $2(4)$ & $10(20)$ & $3(6)$ \\
Antenatal steroids & $19(38)$ & $27(54)$ & $24(48)$ \\
\hline
\end{tabular}

Table 2 Outcome according to ethnic origin (data expressed as median (range) or $n(\%)$ )

\begin{tabular}{lccc}
\hline Respiratory distress syndrome & $20(40)$ & $37(74)$ & $27(54)$ \\
Congenital pneumonia & $8(16)$ & $3(6)$ & $1(2)$ \\
Transient tachypnoea of the newborn & $5(10)$ & $1(2)$ & $3(6)$ \\
Respiratory distress & $17(34)$ & $9(18)$ & $19(38)$ \\
Ventilation & $42(84)$ & $47(94)$ & $45(90)$ \\
Maximum peak inspiratory pressure $\left(\mathrm{cm} \mathrm{H}_{2} \mathrm{O}\right)$ & $18(13-29)$ & $20(14-40)$ & $18(12-32)$ \\
Duration of ventilation (days) & $6(0-38)$ & $7(0-49)$ & $4(0-46)$ \\
Duration of $\mathrm{O}_{2}$ dependency (days) & $12(0-112)$ & $13(5-105)$ & $8(0-68)$ \\
Death & $8(16)$ & $11(22)$ & $11(22)$ \\
\hline
\end{tabular}

had a chest radiograph appearance which showed increased vascular markings, fluid in the horizontal fissure, and overinflation of the lung. ${ }^{8}$ Congenital pneumonia was diagnosed if there was chest radiographic evidence of pneumonitis - that is, asymmetrical consolidation, with or without positive blood cultures. Respiratory distress was diagnosed if the infant required supplementary oxygen or ventilatory support, but did not have an abnormal chest radiograph appearance.

Differences in maternal characteristics and in diagnoses of infant respiratory failure in the three ethnic groups were assessed for significance using $\chi^{2}$ tests. Multiple logistic regression, with presence or absence of RDS as the dependent variable, was used to investigate the effect of ethnic origin on this outcome after controlling for gestational age, size for dates, antenatal steroids, hypertension during pregnancy, PROM, maternal smoking, mode of delivery and infant gender. Non-linear effects of gestational age were not evident, using the various methods suggested by Hosmer and Lemeshow. ${ }^{9}$ Thus gestational age was treated as a continuous variable. Sizes for dates were grouped into four categories for the regression analysis $(<25$ th centile, $25-50$ th centile, 50 75 th centile, and $>75$ th centile). The remaining variables were dichotomous.

Fifty subjects were each matched with an infant of caucasian and Caribbean descent (table 1). There were no significant differences between the three groups with regard to the gender distribution or the proportions who were small for gestational age. The caucasian and Caribbean infants had birthweights usually within $10 \%$ of those of the African infants;

Table 3 Relation between RDS and ethnic origin
26 of the caucasian and 19 of the Caribbean infants were heavier than their matched subject. All patients had been incorporated into the hospital's standard policies. In particular, antenatal steroids were given to all women if a preterm delivery was predicted and there was no evidence of maternal septicaemia; diabetes and hypertension were not contraindications. Infants less than 29 weeks of gestational age were routinely intubated in the delivery suite; more mature infants only for resuscitation purposes. Infants would then remain intubated and ventilated until arterial blood gas estimation on arrival at intensive care showed this to be unnecessary. Surfactant replacement was given in the first four hours of life to infants whose chest radiograph appearance was suggestive of RDS (see above), who were ventilated, and who required an inspired oxygen concentration of more than 0.29 .

\section{Results}

The only significant difference in the maternal characteristics among the three groups was in the proportion who smoked $\left(\chi^{2}=8.44, \mathrm{df}=2\right.$, $\mathrm{p}<0.02)$, smoking being most common in the caucasian group (table 1). The proportions of infants in the three groups who were diagnosed with RDS, congenital pneumonia, TTN and respiratory distress are shown in table 2, along with the other infant outcomes. Each infant received one of these four diagnoses. A diagnosis of congenital pneumonia or of TTN was comparatively rare, so that a statistical analysis which distinguished these diagnoses was not feasible. When numbers of infants with RDS were compared with numbers of infants without RDS, a significant effect of ethnic origin was observed $\left(\chi^{2}=11.9, \mathrm{df}=2, \mathrm{p}<0.005\right)$. Table 3 shows odds ratios and their confidence intervals for RDS in Caribbean and caucasian infants relative to African infants. It also shows how these odds ratios were relatively unchanged even after being adjusted to take account of gestational age, size for dates, antenatal steroids, hypertension during pregnancy, PROM, maternal smoking, mode of delivery and infant gender. The overall effect of ethnic origin was still significant when allowing for the effects of these other potential risk factors $\left(\chi^{2}=9.84\right.$, $\mathrm{df}=2, \mathrm{p}<0.01)$. Table 3 shows that the incidence of RDS was significantly higher in caucasian infants than in African infants, while the incidence in Caribbean infants and in African infants did not differ significantly.

\section{Discussion}

We have shown a lower incidence of RDS in African (significant) and Caribbean (nonsignificant) infants than in caucasian infants,

\begin{tabular}{lll}
\hline & $\begin{array}{l}\text { Odds ratio for RDS, relative to African infants (with 95\% } \\
\text { confidence intervals) }\end{array}$ & Caribbean infants \\
\cline { 2 - 3 } $\begin{array}{l}\text { Variables controlled for in the logistic regression } \\
\text { Caucasian infants }\end{array}$ & $1.8(0.8-3.9)$ \\
\hline $\begin{array}{l}\text { None } \\
\begin{array}{l}\text { Gestational age and size for dates } \\
\text { hypertension during pregnancy, PROM, maternal smoking, } \\
\text { mode of delivery and infant gender }\end{array}\end{array}$ & $4.3(1.8-10.0)$ & $1.8(0.8-4.1)$ \\
\hline
\end{tabular}


implying faster lung maturation in the very prematurely born black babies. The tendency for longer requirement for ventilation and supplementary oxygen (table 2) suggest that the caucasian infants also had more severe respiratory failure. More African infants had congenital pneumonia, and interestingly, a greater proportion of African mothers had had premature rupture of the membranes. The respiratory diagnoses of all of the infants had been made by the clinician in charge using standard criteria and were not influenced by this study, as it was retrospective.

Black, rather than white, infants have a systematic tendency to be born at lower gestational ages, to weigh less at birth, ${ }^{10-12}$ with a greater proportion of them weighing less than 2500 g. ${ }^{1}$ These factors are known to influence the occurrence of RDS. ${ }^{13-16}$ We therefore took care to avoid such bias by matching the infants for gestational age, and the matching process not only considered gestational age and birth order, but gender and birth date if several eligible infants were identified. Our three groups were of similar birthweights, so there were no significant differences in the proportion of infants who were SGA in the three groups. This study was performed retrospectively, but 50 of the 60 eligible African infants eligible for entry were studied, the remaining infants being excluded only because it was not possible to match them with both a Caribbean and caucasian infant.

These results suggest that the association between ethnicity and lung maturation is complex. ${ }^{6}$ A larger difference in the incidence of RDS was noted between the African and caucasian infants than between the Caribbean and caucasian infants. Higher lecithin:sphingomyelin (L:S) ratios related to gestational age have been reported in certain black infants, ${ }^{3}$ but results from Nigerian babies have, however, only been compared with those of a reported series. The lower rate of RDS may not only be due to surfactant status, as even at low $\mathrm{L}: \mathrm{S}$ ratios $(1: 1.2)$ cases of $\mathrm{RDS}$ in white, but not black infants have been reported. ${ }^{2}$ Other explanations to consider are differences in anatomic structure ${ }^{2}$ or surfactant proteins. ${ }^{17}$ Allelic variation of the surfactant protein A gene has been reported between American whites and Nigerian blacks. ${ }^{17}$

The prophylactic effect of antenatal steroids on the development of RDS may be particularly efficacious in non-caucasians, ${ }^{18}$ but this is controversial, ${ }^{19}$ and does not explain the present results; the African infants had both the lowest incidence of RDS and the lowest administration of antenatal steroids. Other maternal factors such as PROM may also have a positive influence on RDS, ${ }^{20}$ although this is also debated. ${ }^{21}$ In the present study the incidence of PROM was higher in the African population, but this did not reach significance. We also performed regression analysis, including PROM and other maternal factors known to influence RDS, and this showed that RDS was independently related to ethnic origin.

It has been suggested that environmental factors in the mother such as smoking might explain some of the differences apparently due to ethnicity. ${ }^{6}$ Smoking does influence lung maturation $^{6}$ and a possible mechanism might be a reduction in uteroplacental blood flow $^{22}$ which can increase lung maturation. ${ }^{23}$ Interestingly, in this study a greater proportion of caucasian mothers smoked and thus this cannot explain our results. A review of infants born between 26 and 37 weeks in the USA between 1982 and 1987 demonstrated differences related to ethnic origin in the duration of medical education, occurrence of PROM, anaemia and chronic hypertension. ${ }^{24}$ In that relatively mature group (only $5 \%$ of the infants were VLBW and their median gestational age was 36 weeks), however, the differences in the incidence of RDS related to ethnic origin remained after controlling for population differences. Nevertheless, unmeasured ethnic differences in economic, nutritional, or disease conditions may underlie the ethnic disparities in RDS incidence. ${ }^{24}$ The results of one study ${ }^{3}$ have suggested the rates of lung maturation were inversely related to maternal body weight. Undernourished mothers have been reported to have low blood pressures and in that group increasing blood pressure to even normal levels had striking effects on fetal growth rate. ${ }^{25}$ Differences in uteroplacental blood flow could thus explain a possible effect of differences in nutrition, as a reduction in uteroplacental blood flow would be predicted with low blood pressure.

It has been suggested that the effect of ethnicity may not be apparent until 32 weeks of gestation. ${ }^{5}$ Nevertheless, in this review of infants born at less than 33 weeks of gestation, a difference in the incidence of RDS was noted. These data have important implications for clinical management - for example, regarding the timing of interventions such as induction of preterm labour. The exact mechanism of accelerated lung maturation in black infants requires further investigation, as the factors which stimulate fetal lung development in such babies might be applicable to other ethnic groups. ${ }^{24}$

1 Fujikura T, Froehlich LA. The influence of race and other factors on pulmonary hyaline membranes. Am $\mathcal{F}$ Obstet Gynecol 1966;95:572-9.

2 Richardson DK, Torday JS. Racial differences in predictive value of the lecithin/sphingomyelin ratio. Am $f$ Obstet Gynecol 1994;170:1273-8.

3 Olowe SA, Akinkugbe A. Amniotic fluid lecithin/ sphingomyelin ratio: comparison between an African and a North American community. Pediatrics 1978;62:38-41.

4 Bryan H, Hawrylyshyn P, Hogg-Johnson S, et al. Perinatal factors associated with the respiratory distress syndrome. Am f Obstet Gynecol 1990;162:476-81.

5 Robillard P-Y, Hulsey TC, Alexander CR, Sergent M-P, de Caunes F, Papiernik E. Hyaline membrane disease in baunes F, Papiernik E. Hyaline membrane disease in black newborns: does fetal lung matura

6 Ross S, Naeye RL. Racial and environmental influences on fetal lung maturation. Pediatrics 1981;68:790-5.

7 Greenough A. Respiratory distress syndrome. Curr Paediatr 1992;2:41-5

8 Greenough A, Lagercrantz $\mathrm{H}$. Catecholamine abnormalities in transient tachypnoea of the premature newborn. $\mathcal{F}$ Perinat Med 1992;20:223-6.

9 Hosmer DW, Lemeshow S. Applied logistic regression. New York: John Wiley \& Sons, 1989

10 Kerr GR, Verrier M, Ying J, Spears W. Proportional differences in births and infant mortality rates among the triethnic population in Texas from 1984 through 1986. Texas Med 1995;91:50-7.

11 Lyon A, Clarkson P, Jeffrey I, West G. Effect of ethnic origin of mother on fetal outcome. Arch Dis Child 1994;70:F40- 
12 Kleinman J, Kessl S. Racial differences in low birthweight. N Engl F Med 1987;317:749-53.

13 Stanley $\mathrm{F}$, Alberman $\mathrm{E}$. Infants of very low birth weight. II Perinatal factors in and conditions associated with RDS Dev Med Child Neurol 1978;20:313-22.

14 Hack M, Horbar J, Malloy M, Tyson J, Wright E, Wright L. Very low birthweight outcomes of the National Institute of Child Health and Human Development Neonatal Network. Pediatrics 1991;87:587-96.

15 Lankenau H. A genetic and statistical study of the respiratory distress syndrome. Eur f Pediatr 1976;123:16677.

16 Luerti M, Parazzini F, et al. Risk factors for respiratory distress syndrome in the newborn. Acta Obstet Gynecol Scand 1993;72:359-64

17 Rishi A, Hatzis D, McAlmon F, Floros J. An allelic variant of the 6A gene for surfactant protein A. Am $\mathcal{F}$ Physiol the 6A gene for

18 Collaborative group on antenatal steroid therapy. Effect of antenatal dexamethasone administration on the prevenantenatal dexamethasone administration on the preven-
tion of respiratory distress syndrome. Am f Obstet Gynecol 1981;141:276-87.
19 National Institute of Health Consensus Development Conference Statement. Effect of corticosteroids for fetal matuference Statement. Effect of corticosteroids for fetal matu-
ration on perinatal outcomes, February 28-March 2, 1994. ration on perinatal outcomes, February

20 Bauer CR, Stern L, Colle E. Prolonged rupture of the memBauer CR, Stern L, Colle E. Prolonged rupture of the mem-
branes, associated with a decreased incidence of RDS. Pediatrics 1974;53:7-12

21 Hallak M, Bottoms SF. Accelerated pulmonary maturation from preterm premature rupture of the membranes: a myth. Am f Obstet Gynecol 1993;169:1045-9.

22 Naeye RL. Effects of maternal cigarette smoking on the fetus and placenta. Br f Obstet Gynaecol 1978;85:732.

23 Gluck L, Kulovich MO. Lecithin/sphingomyelin ratios in amniotic fluid in normal and abnormal pregnancy. $A m \mathcal{F}$ Obstet Gynecol 1973;115:539.

24 Hulsey TC, Alexander GR, Robillard PY, Annibale DJ, Keenan A. Hyaline membrane disease: the role of ethnicity and maternal risk characteristics. Am F Obstet Gynecol 1993;168:572-6.

25 Grunberger W, Leodolter S, Parschalk O. Maternal hypotension, fetal outcomes in treated and untreated cases. Gynecol Obstet Invest 1979;10:32-8. 